\title{
Estimasi Biomassa dan Simpanan Karbon pada Vegetasi Lamun di Perairan Pantai Jepara
}

\author{
Radila Widya Shafiya*, Ali Djunaedi, Raden Ario \\ Departemen IImu Kelautan, Fakultas Perikanan dan IImu Kelautan, Universitas Diponegoro \\ JI. Prof. H. Soedarto S.H, Tembalang, Semarang, Jawa Tengah 50275 Indonesia \\ ${ }^{*}$ Corresponding author, e-mail : radilashafiya98@gmail.com
}

\begin{abstract}
ABSTRAK: Peningkatan emisi karbon yang berasal dari berbagai aktivitas manusisa dapat mengakibatkan terjadinya pemanasan global. Salah satu upaya untuk mengurangi emisi gas karbon adalah dengan memanfaatkan vegetasi pesisir seperti lamun yang dikenal dengan istilah blue carbon. Ekosistem lamun merupakan salah satu ekosistem pesisir yang dapat menyerap dan menyimpan karbon dalam jumlah yang besar dan dalam waktu yang lama. Penelitian ini bertujuan untuk mengetahui kerapatan, tutupan lamun, nilai biomassa dan simpanan karbon pada lamun di Pantai Blebak dan Pantai Prawean, Kabupaten Jepara. Metode survei dan penentuan lokasi dipilih dengan menggunakan metode purposive sampling, sedangkan metode pengambilan data lamun melalui metode line transect quadrant dengan ukuran $50 \times 50 \mathrm{~cm}$ yang mengacu pada metode LIPI 2017. Perhitungan kandungan karbon menggunakan metode Loss On Ignition (LOI). Hasil kerapatan lamun total pada Pantai Prawean yaitu sebesar $221,45 \mathrm{ind} / \mathrm{m}^{2}$ dan nilai tutupan total lamun sebesar $45,98 \%$. Kerapatan lamun total pada Pantai Blebak yaitu sebesar $160 \mathrm{ind} / \mathrm{m}^{2}$ dan nilai tutupan total lamun sebesar $41,67 \%$. Nilai biomassa bawah substrat dan atas substrat pada Pantai Prawean $\left(726,25 \mathrm{gbk} / \mathrm{m}^{2}\right.$ dan $\left.500,50 \mathrm{gbk} / \mathrm{m}^{2}\right)$ menunjukkan nilai yang lebih besar dibandingkan nilai biomassa bawah substrat dan atas substrat pada Pantai Blebak $\left(606,50 \mathrm{gbk} / \mathrm{m}^{2}\right.$ dan $370,75 \mathrm{gbk} / \mathrm{m}^{2}$ ). Total kandungan karbon pada Pantai Prawean adalah $464,10 \mathrm{gC} / \mathrm{m}^{2}$ sedangkan pada Pantai Blebak adalah $357,79 \mathrm{gC} / \mathrm{m}^{2}$. Hasil perhitungan total stok karbon yang didapatkan menunjukkan bahwa Pantai Prawean memiliki nilai biomassa dan total stok karbon yang lebih tinggi daripada Pantai Blebak.
\end{abstract}

Kata Kunci : Biomassa; Blue Karbon; Jepara; Karbon; Lamun

\section{Estimation Biomass and Carbon Stock in Seagrass at Prawean and Blebak Beach Jepara}

ABSTRACT : Human activities lead to the increasing of carbon emission, which caused global warming. Seagrass and other coastal vegetation are being used to reduce carbon emission. This is known as blue carbon. The seagrass ecosystem is one of coastal ecosystem that can absorb and stock high amount of carbon in a short period of time. This study was done to determine the density, seagrass coverage, biomass, and carbon stock within the seagrass in Prawean and Blebak Beach, Jepara. Survey method and location determination method were done with purposive sampling method. Whereas, the seagrass data was collected by Line Transect Quadrant method 50x50 cm based on LIPl's 2017 method. Loss on Ignition method was used to measure the carbon's content. The density of total seagrass in Prawean beach is $221,45 \mathrm{ind} / \mathrm{m}^{2}$ and the total percentage of seagrass coverage is $45,98 \%$. Total density of seagrass in Blebak Beach is 160 ind $/ \mathrm{m}^{2}$ with a coverage percentage of $41,67 \%$. The biomass below the substrate level and above the substrate level in Prawean Beach $\left(726,25 \mathrm{gbk} / \mathrm{m}^{2}\right.$ and $\left.500,50 \mathrm{gbk} / \mathrm{m}^{2}\right)$ showed a bigger amount than the amount of biomass in Blebak Beach $\left(606,50 \mathrm{gbk} / \mathrm{m}^{2}\right.$ and $\left.370,75 \mathrm{gbk} / \mathrm{m}^{2}\right)$. Total amount of carbon in Prawean is $464,10 \mathrm{gC} / \mathrm{m}^{2}$ meanwhile in Blebak, the amount of carbon is $357,79 \mathrm{gC} / \mathrm{m}^{2}$. The results of the total carbon stock obtained indicate that Prawean Beach has higher biomass and total carbon stock values than Blebak Beach.

Keywords : Biomass; Blue Karbon; Carbon; Jepara; Seagrass 


\section{PENDAHULUAN}

Perubahan iklim (climate change) merupakan akibat dari pemanasan global (global warming). Hal ini terjadi akibat Gas Rumah Kaca (GRK) yang terakumulasi di atmosfer. Jenis gas tersebut yaitu metana $(\mathrm{CH} 4)$ dan dinitrogen oksida (N2O), dan karbon dioksida (CO2). Karbon dioksida (CO2) merupakan penyumbang terbesar yaitu 55\% dari kandungan gas rumah kaca (Smith et al, 2004). Konsentrasi karbondioksida (CO2) di atmosfer cenderung meningkat dari tahun ke tahun, dan akan terus meningkat sejalan dengan meningkatnya budidaya pertanian dan industri global (IPCC, 2001). Laut dan ekosistem pesisir pantai dapat menyerap karbon dalam jumlah yang besar dan dalam jangka waktu relatif lama, serta memiliki produksi primer bersih (net primary production/NPP) yang signifikan (Larkum et al., 2006).

Tahun 2009 konsep blue carbon dirilis atas kerjasama antara United Nations Environment Programme, Food and Agriculture Organization dan United Nations Educational, Scientific and Cultural Organization. Konsep tersebut dilandasi oleh kemampuan ketiga ekosistem laut (mangrove, lamun dan rawa asin) dalam menjaga keseimbangan penyerapan dan pengurangan emisi karbon dengan ekosistem darat seperti hutan hujan tropis (Nellemann et al., 2009). Salah satu ekosistem pesisir yang memiliki kemampuan menyerap dan meyimpan karbon dalam kurun waktu yang relatif lama adalah padang lamun. Padang lamun dapat menyimpan karbon 3-5 kali lebih cepat dibandingkan hutan hujan tropis, dan dapat mengikat karbon dalam waktu ribuan tahun. Selain itu, ekosistem lamun dapat menangkap sekitar $70 \%$ dari karbon organik total yang berada di laut (Nellemann et al. 2009).

Lamun merupakan tumbuhan berbunga (Angiospermae) yang mampu hidup di lingkungan perairan laut dangkal. Lamun memiliki fungsi sebagai penyerap dan penyimpan karbon. Lamun yang hidup secara terendam didalam perairan dapat melakukan fotosintesis seperti halnya tumbuhan di darat. Proses fotosintesis ini menghasilkan bahan organik dari bahan anorganik berupa karbon, yang kemudian disimpan pada biomassa (Rustam et al., 2013) dan disebut dengan blue carbon. Ekosistem padang lamun mampu menyerap 83.000 metrik ton karbon $/ \mathrm{km}^{2}$. Jumlah ini lebih tinggi dibandingkan kemampuan hutan yang menyerap 30.000 metrik ton karbon/ $\mathrm{km}^{2}$ (Fourqurean et al., 2012).

Nilai estimasi kandungan simpanan karbon pada setiap ekosistem memiliki hasil yang berbeda - beda, hal ini dikarenakan setiap ekosistem memiliki kemampuan penyerapan karbon yang berbeda, tergantung pada kondisi morfologi, jenis ekosistem, kerapatan dan kondisi lingkungan perairannya. Hal ini menyebabkan nilai kandungan stok karbon pada setiap ekosistem pun berbeda-beda (Ulumuddin et al., 2015). Pantai Prawean dan Pantai Blebak tepatnya di Kabupaten Jepara diketahui terdapat ekosistem padang lamun dengan keanekaragaman spesiesnya, hal tersebut didukung oleh penelitian yang dilakukan oleh Septiani et al. (2018) dan Nabilla et al., (2019) sehingga di daerah tersebut diduga berpotensi sebagai penyimpan karbon. Kemampuan dalam menyerap dan menyimpan karbondioksida ini menunjukkan bahwa lamun memiliki peranan penting dalam memitigasi perubahan iklim pada tahun-tahun mendatang (Wawo et al., 2014). Perbedaan karakteristik lingkungan di kedua lokasi tersebut diduga sebagai salah satu faktor yang mempengaruhi kestabilan kondisi perairan, yang diduga akan berdampak pada kelestarian padang lamun yang berfungsi sebagai penyerap karbon. Maka diperlukan penelitian lebih lanjut untuk mengetahui potensi kandungan biomassa dan estimasi simpanan karbon pada lamun dikedua lokasi tersebut.

\section{MATERI METODE}

Penelitian ini dilakukan dengan menggunakan metode penelitian deskriptif eksploratif. Data yang digunakan pada penelitian ini adalah data primer dan data sekunder. Data primer meliputi kerapatan, biomassa dan stock karbon yang ada pada lamun. Data sekunder meliputi parameter kualitas perairan di antaranya suhu, arus, salinitas, $\mathrm{pH}$, DO, Kecerahan, ukuran butir sedimen, nitrat dan fosfat. Penelitian ini dilakukan pada bulan Mei 2020 di 2 lokasi, Pantai Prawean mewakili perairan dengan sedikit aktivitas masyarakat sedangkan Pantai Blebak mewakili perairan dengan aktivitas masyarakat yang padat, seperti aktivitas wisata, tambak, dan termasuk daerah pemukiman yang padat penduduk. 
Metode pendataan lamun dilakukan dengan menggunakan metode line transect quadrant dan seluruh pengamatan yang dilakukan pada metode ini diukur serta diamati secara langsung di lapangan secara visual. Metode ini mengacu pada buku Panduan Monitoring Padang Lamun LIPI (Rahmawati et al., 2014).

Tiga garis transek dibentangkan di setiap titik lokasi setelah melakukan pengamatan lingkungan dengan keadaan lamun yang ada dilokasi tersebut. Transek garis dibentangkan tegak lurus terhadap garis pantai, dimulai dari titik 0 (nol) pada roll meter. Titik 0 (nol) dimulai dari ditemukannya jenis lamun pertama, kemudian ditarik garis ke arah laut lepas sepanjang $100 \mathrm{~m}$. Stasiun pengamatan terdiri dari 3 (tiga) transek garis pengulangan, dengan jarak antar garis ke samping adalah $50 \mathrm{~m}$. Jarak antara transek kuadrat dalam satu garis transek adalah $10 \mathrm{~m}$, pengulangan dilakukan sampai ujung garis transek mencapai 100 m (Rahmawati et al., 2014).

Pengambilan sampel biomassa lamun mengikuti metode dalam buku panduan pengukuran karbon lamun yang ditulis oleh Rustam et al. (2019). Plot yang digunakan untuk mengambil sampel biomassa lamun adalah kuadrant berukuran 20x20 cm yang dimasukkan ke dalam substrat yang terdapat lamun di atasnya. Sekop kecil dibenamkan ke dalam substrat di setiap sisi kuadrant $20 \mathrm{~cm}$ x $20 \mathrm{~cm}$ untuk kemudian diambil sampelnya. Biomassa sampel lamun dapat diukur setelah dilakukan proses pengeringan dan penimbangan berat per bagian tegakan lamun di laboratorium dengan cara memasukkan ke dalam oven pada temperature suhu tetap $60^{\circ} \mathrm{C}$ selama 4-5 jam atau hingga sampel mencapai berat konstan. Pengukuran biomassa per tegakan lamun dapat diketahui dengan membagi berat total setiap sampel dengan jumlah tegakannya (kerapatan).

Nilai kandungan karbon pada sampel jaringan lamun (daun, rhizoma dan akar) dianalisis dengan menggunakan metode LOI (Loss on Ignition) atau disebut sebagai metode abu menggunakan persamaan oleh Helrich (1990) untuk kemudian dirata-rata sebagai nilai kandungan karbon yang terdapat pada jaringan tumbuhan lamun (Graha, 2015). Sampel dalam cawan porselen dimasukkan ke dalam tanur dan dipijarkan pada suhu $450-550{ }^{\circ} \mathrm{C}$ selama \pm 4 jam. Sampel dalam cawan porselen didinginkan di dalam desikator kemudian ditimbang.
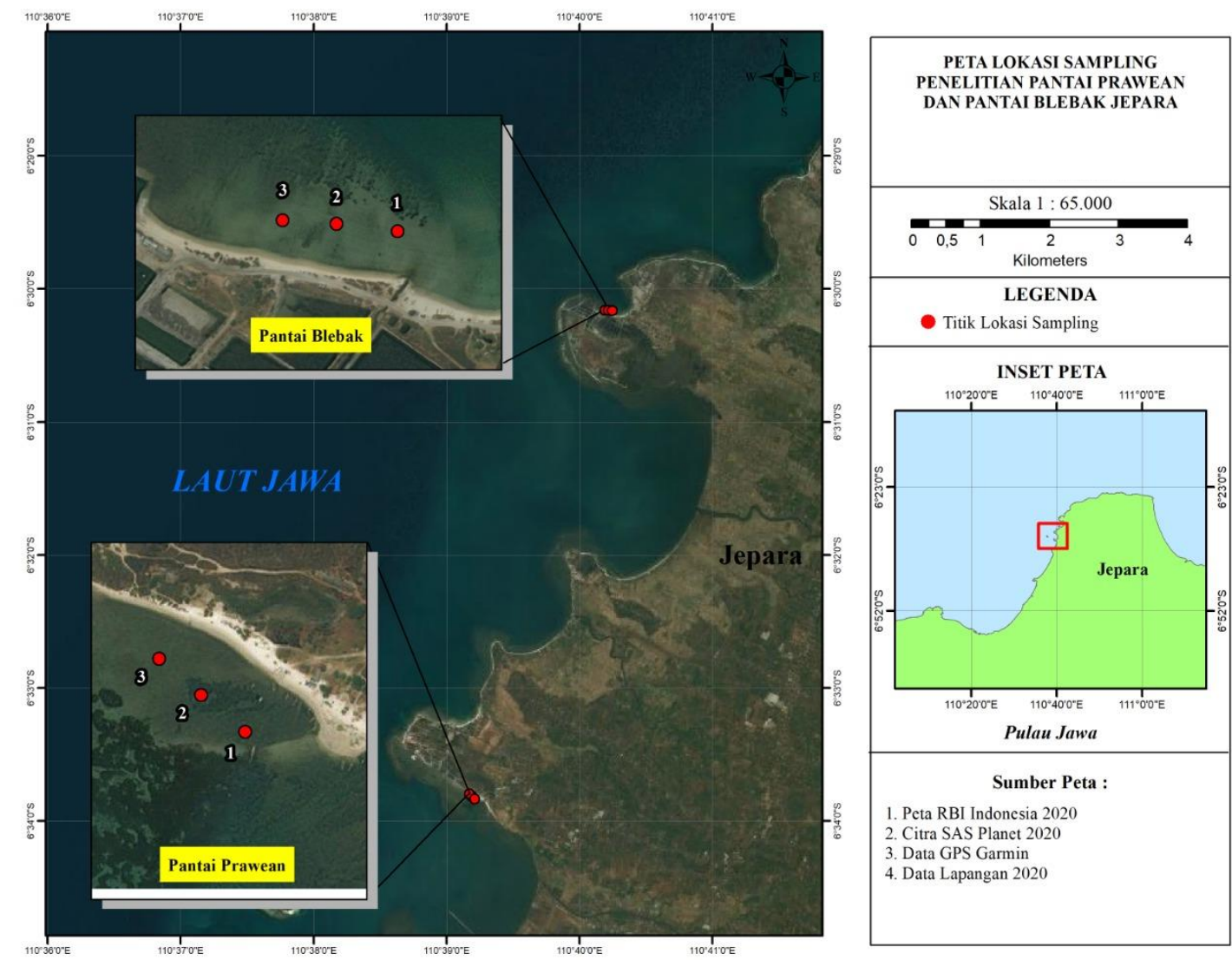

Gambar 1. Lokasi penelitian Pantai Prawean dan Pantai Blebak 


\section{HASIL DAN PEMBAHASAN}

Jenis lamun yang ditemukan di Pantai Prawean dan Pantai Blebak adalah Enhalus acoroides, Cymodocea serrulata, Cymodocea rotundata, Thalassia hemprichii, dan Halodule uninervis. Hasil Kerapatan dan Tutupan cover pada Tabel 1. Hasil penelitian menunjukan bahwa nilai total estimasi biomassa pada Pantai Prawean lebih tinggi daripada Pantai Blebak, hal ini disebabkan nilai total kerapatan lamun pada Pantai Prawean lebih besar daripada Pantai Blebak (Tabel 2). Menurut Setiawan et al. (2012), biomassa dipengaruhi oleh kerapatan lamun, semakin besar kerapatan pada suatu daerah maka semakin besar pula biomassa tumbuhan yang terdapat di dalamnya. Thallasia hempricii merupakan lamun yang memiliki biomassa tertinggi pada semua stasiun dan menjadi penyumbang terbesar biomassa total pada ekosistem lamun, sedangkan nilai biomassa terendah yaitu jenis Halodule uninervis. Hal ini karena morfologi lamun jenis Thalassia hempricii lebih cenderung berukuran besar daripada lamun jenis Halodule uninervis. Menurut Laffoley dan Grimsditch (2009), jenis lamun yang secara morfologi berukuran besar cenderung mengembangkan biomassa yang tinggi.

Hasil pengukuran nilai kerapatan dengan biomassa jenis lamun di Pantai Prawean tidak menunjukkan hasil yang berbanding lurus, dimana tidak semua jenis lamun dengan kerapatan yang tinggi dapat menghasilkan biomassa dalam jumlah yang besar. Hal ini didapati pada jenis Cymodocea serrulata yang memiliki kerapatan total tertinggi di Pantai Prawean justru tidak memiliki biomassa tertinggi, karena jenis yang mendominasi biomassa tertinggi di perairan ini adalah lamun jenis Thallasia hempricii. Species lamun yang secara morfologi berukuran besar seperti Thallasia hempricii cenderung memiliki nilai biomassa lebih tinggi terutama biomassa yang terdapat di bawah susbstrat.

Hasil yang didapatkan, nilai biomassa kedua lokasi pada bagian bawah subtrat lebih besar dari biomassa pada atas substrat. Hal ini sesuai dengan pernyataan Hemminga dan Duarte (1990), bahwa biomassa lamun umumnya lebih besar tersimpan pada bagian bawah substrat (below ground) dibandingkan dengan bagian atas substrat (above ground). Diperkuat dengan Wahyudi et al., (2016) yang menyatakan bahwa rata-rata biomassa lebih tinggi di bagian bawah substrat dibandingkan dengan atas substrat, hal ini dikarenakan materi biomassa yang terbentuk di bagian bawah substrat umumnya berupa biomassa yang lebih padat dibandingkan dengan biomassa diatas substrat seperti daun. Dikarenakan rhizoma mengandung banyak zat pati dan unsur hara dimana zat tersebut di distribusikkan dari hasil foto sintesis yang disimpan pada bagian bawah substrat, sehingga biomassa pada rhizoma dibawah substrat lebih tinggi apabila dibandingkan

Tabel 1. Kerapatan Lamun (ind $/ \mathrm{m}^{2}$ ) dan Persentase Tutupan Lamun (\%) di Pantai Prawean dan Pantai Blebak

\begin{tabular}{lrrrr}
\hline \multirow{2}{*}{ Spesies } & \multicolumn{2}{c}{ Pantai Prawean } & \multicolumn{2}{c}{ Pantai Blebak } \\
\cline { 2 - 5 } & $\left(\right.$ ind $\left./ \mathrm{m}^{2}\right)$ & $\%$ Cover & \multicolumn{1}{c}{$\left(\right.$ ind $\left./ \mathrm{m}^{2}\right)$} & \% Cover \\
\hline Enhalus acoroides & 7,88 & 2,99 & 6,18 & 0,83 \\
Thalassia hempricii & 89,09 & 21,93 & 105,58 & 28,59 \\
Cymodocea rotundata & 4,36 & 0,94 & - & - \\
Cymodocea serrulata & 97,82 & 17,08 & 24,24 & 5,87 \\
Halodule uninervis & 22,30 & 3,03 & 24 & 6,36 \\
\hline \multicolumn{1}{c}{$\Sigma$} & 221,45 & 45,98 & 160 & 41,67 \\
\hline
\end{tabular}

Tabel 2. Nilai Total Biomassa $\left(\mathrm{gbk} / \mathrm{m}^{2}\right)$ Lamun di Pantai Prawean dan Pantai Blebak

\begin{tabular}{cccc}
\hline \multirow{2}{*}{ Lokasi } & \multicolumn{3}{c}{ Total Biomassa } \\
\cline { 2 - 4 } & Bawah Substrat & Atas Substrat & Total \\
\hline Pantai Prawean & 726,25 & 500,50 & 1226,75 \\
Pantai Blebak & 606,50 & 370,75 & 977,25 \\
\hline
\end{tabular}


dengan jaringan lainya (Erftemeijer et al., 1993). Tingginya biomassa dibagian bawah substrat tentunya memiliki tujuan dalam menjaga kelangsungan kehidupan lamun itu sendiri, salah satu fungsi besarnya penyimpanan biomassa di bawah substrat adalah untuk memperkuat penancapan pada substrat. Tasabaramo et al., (2016) menyatakan bahwa nilai biomassa yang berada dibawah substrat berasal dari nutrisi yang diserap oleh akar pada sedimen serta material organik hasil fotosintesis yang sebagian besar disimpan pada rhizoma yang berkaitan erat dengan daya tancap lamun pada substrat untuk bertahan dari arus dan gelombang laut.

Hasil perhitungan stok karbon lamun pada kedua lokasi menunjukan bahwa stok karbon lamun di Pantai Prawean dan Pantai Blebak memiliki kandungan yang lebih besar pada bagian bawah substrat dibandingkan dengan stok karbon pada bagian atas substrat (Tabel 3). Hal tersebut karena karbon dibawah substrat tidak banyak terpengaruh oleh kondisi fisik lingkungan daripada karbon dibawah substrat. Supriadi et al., (2014), menyatakan bahwa disebabkan oleh karbon di bawah substrat tidak terlalu terpengaruh oleh pengaruh fisik lingkungan sebagaimana simpanan karbon yang ada di bagian atas substrat. Simpanan karbon dibagian atas susbtrat relatif berfluktuasi dibandingkan dengan simpanan karbon bagian bawah subtrat, walaupun berfluktuasi namun simpanan karbon di atas substrat akan tetap terpelihara selama tunas lamun masih hidup.

Kemampuan menyerap karbon umumnya berbeda di antar tiap jenis lamun. Perbedaan ini dapat disebabkan oleh faktor internal yang berasal dari lamun sendiri seperti morfologi dan metabolisme jenis lamun. Berdasarkan hasil yang didapatkan, nilai total stok karbon dipengaruhi oleh morfologi spesies lamun itu sendiri. Halodule uninervis memiliki stok karbon total lebih rendah karena jumlahnya yang lebih sedikit, lokasi pertumbuhannya yang jarang dan ukuran daun, batang serta akarnya lebih kecil, sedangkan Thalassia hempricii memiliki stok karbon yang tinggi karena jumlahnya yang banyak dan lokasi pertumbuhan yang menyebar serta ukuran daun, batang dan akar yang lebih besar dan tebal. Menurut Indriani et al., (2017) Spesies lamun yang secara morfologi berukuran besar cenderung menyimpan biomassa yang lebih besar di bagian bawah substrat (BS) sehingga kapasitas untuk mengakumulasi karbon menjadi semakin tinggi.

Hasil perhitungan total stok karbon yang didapatkan menunjukkan bahwa Pantai Prawean memiliki nilai total stok karbon yang lebih tinggi daripada Pantai Blebak (Tabel 3), hal tersebut disebabkan oleh nilai total biomassa pada Pantai Prawean yang lebih tinggi dari Pantai Blebak. Graha (2015), menyatakan variasi kandungan karbon lamun dipengaruhi oleh perbedaan biomassa antar jenis ataupun jaringan. Semakin tinggi kandungan biomassa pada lamun maka nilai kandungan karbon pada jaringan lamun juga semakin meningkat, yang artinya nilai kandungan karbon berbanding lurus dengan kandungan nilai biomassa pada lamun (Wardah et al., 2009). Nilai biomassa pada bagian lamun dipengaruhi oleh morfologi jenis lamun yang ditemukan, semakin besar morfologi lamun tersebut maka cenderung akan menyimpan biomassa yang lebih besar pada bagian bawah substrat dan kapasitas untuk mengakumulasi karbon menjadi semakin tinggi (Laffoley dan Grmsditch, 2009).

Nilai total stok karbon lamun yang lebih tinggi di Pantai Prawean juga disebabkan karena lokasi ini memiliki nilai total kerapatan dan persentase penutupan lamun yang lebih tinggi pula (Tabel 3). Hal tersebut karena adanya perbedaan kondisi parameter pada lokasi lamun tersebut tumbuh. Parameter tersebut dapat berupa parameter fisik dan kimia, dimana setiap perairan memiliki karakteristik tersendiri karena adanya faktor yang mempengaruhi kondisi di perairan tersebut (Papilo et al., 2015).

Nilai total stok karbon yang tinggi pada Pantai Prawean dapat menjelaskan bahwa kondisi daerah tersebut baik bagi tempat hidup lamun meskipun terdapat aktifitas antropogenik (kapal), tetapi dampak yang ditimbulkan tidak berpengaruh besar terhadap lamun yang ada. Hal ini berbeda dengan Pantai Blebak, penyebab rendahnya estimasi simpanan karbon pada lokasi ini disebabkan oleh adanya pengaruh aktivitas antropogenik maupun aktivitas fisik pada perairan tersebut.

Tabel 3. Nilai Total Estimasi Stok Karbon $\left(\mathrm{gC} / \mathrm{m}^{2}\right)$ di Pantai Prawean dan Pantai Blebak

\begin{tabular}{cccc}
\hline \multirow{2}{*}{ Lokasi } & \multicolumn{3}{c}{ Total Stok Karbon $\left(\mathrm{gC} / \mathrm{m}^{2}\right)$} \\
\cline { 2 - 4 } & Atas Substrat & Bawah substrat & Total \\
\hline Pantai Prawean & 198,93 & 265,17 & 464,10 \\
Pantai Blebak & 139,39 & 218,40 & 357,79 \\
\hline
\end{tabular}


Banyak aktivitas wisatawan dan pemancing disekitar lamun di Pantai Blebak membuat lamun rusak, sulit tumbuh dan berkembang dengan baik sehingga berpengaruh terhadap simpanan karbon pada daerah tersebut. McKenzie et al., (2003) menyatakan aktivitas manusia yang berlebihan pada ekosistem padang lamun juga akan mempengaruhi padang lamun tersebut, tingginya aktivitas manusia akan menyebabkan lamun akan mengalami stress dan dapat menyebabkan kematian. Diperkuat oleh Travaille et al., (2015) dan Eckrich \& Holmquist (2000), kegiatan wisata yang menyebabkan terinjak-injaknya lamun mengakibatkan penurunan kerapatan lamun. Limbah dari kegiatan pariwisata juga dapat menyebabkan penurunan kualitas air.

Hasil penelitian estimasi stok karbon pada penelitian ini lebih tinggi dibandingkan dengan penelitian Indriani et al., (2016) Teluk Bakau dan Pengudang Pesisir Pulau Bintan, Kepulauan Riau yaitu $110,51 \mathrm{gC} / \mathrm{m}^{2}$ dan 153,88 gC/m². Hal ini dikarenakan Teluk Bakau dan Pengudang memiliki kategori tutupan lamun yang rendah, sehingga berkorelasi dengan biomassa dan kandungan karbon pada lamun tersebut juga rendah. Wouthuyzen (2015), Wahyudi et al. (2016) , menyatakan bahwa pada tahun 2015 luas eskosistem lamun di Kabupaten Bintan menurun hingga 2600 ha. Hal ini diduga menjadi penyebab rendahnya nilai estimasi stok karbon pada Teluk Bakau dan Pengudang, di Pesisir Pulau Bintan.

Jumlah stok karbon dari ekosistem lamun dapat menunjukan nilai banyaknya CO2 yang dapat diserap oleh ekosistem tersebut. Semakin besar nilai stok karbon dari suatu ekosistem akan semakin baik, karena dapat memberikan kontribusi besar dalam proses mitigasi perubahan iklim. Menurut Howard et al. (2014), ekosistem lamun memiliki kemampuan yang baik dalam menyimpan karbon. Ekosistem lamun dapat menyimpan karbon dalam waktu yang lebih lama dibandingkan ekosistem terestrial. Oleh karena itu, pengelolaan wilayah pesisir untuk menjaga ekosistem lamun sangat diperlukan, sehingga penyerapan $\mathrm{CO} 2$ oleh ekosistem lamun dapat meningkat. Peningkatan penyerapan $\mathrm{CO} 2$ dari atmosfer sangat diperlukanuntuk mengurangi dampak pemanasan global.

\section{KESIMPULAN}

Berdasarkan hasil penelitian yang telah di lakukan pada lamun di Pantai Prawean dan Pantai Blebak, Perairan Jepara didapatkan nilai biomassa lamun pada bawah dan atas substrat di Pantai Prawean sebesar $726,25 \mathrm{gbk} / \mathrm{m}^{2}$ dan $500,5 \mathrm{gbk} / \mathrm{m}^{2}$. Nilai biomassa lamun pada bawah dan atas substrat di Pantai Blebak sebesar dan $606,5 \mathrm{gbk} / \mathrm{m}^{2}$ dan $370,75 \mathrm{gbk} / \mathrm{m}^{2}$. Nilai total biomassa lamun di Pantai Prawean dan Pantai Blebak sebesar 1226,75 gbk/m² dan $977,25 \mathrm{gbk} / \mathrm{m}^{2}$. Nilai stok karbon lamun pada bawah dan atas substrat di Pantai Prawean sebesar 198,93 gC/m² dan $265,17 \mathrm{gC} / \mathrm{m}^{2}$. Nilai stok karbon lamun pada bawah dan atas substrat di Pantai Blebak sebesar dan $139,39 \mathrm{gC} / \mathrm{m}^{2}$ dan $218,40 \mathrm{gC} / \mathrm{m}^{2}$. Nilai total stok karbon lamun di Pantai Prawean dan Pantai Blebak sebesar $464,10 \mathrm{gC} / \mathrm{m}^{2}$ dan $357,79 \mathrm{gC} / \mathrm{m}^{2}$. Hasil perhitungan menunjukkan bahwa Pantai Prawean memiliki nilai total biomassa dan stok karbon yang lebih tinggi daripada Pantai Blebak.

\section{DAFTAR PUSTAKA}

Duarte, C.M. 1990. Seagrass Nutrient Content. Marine Ecology Program, 67: 201207.

Eckrich, C.E. \& Holmquist, J.G. 2000. Trampling in a Seagrass Assemblage: Direct Effects, Response of Associated Fauna, and The Role of Substrate Characteristics. Marine Ecology Progress Series 201:199- 209.

Erftemeijer, P.L.A., Osinga, R. \& Mars, A.E. 1993. Primary Production of Seagrass Beds in South Sulawesi (Indonesia): a Comparison of Habits, Method and Species. Aquatic Botany. 46:6790.

Fourqurean, J.W., Duarte, C.M., Kennedy, H., Marba, N., Holmer, M., Mateo, M.A., Apostolaki, E., Kendrick, G.A., Krause-Jensen, D., McGlathery, K.J. \& Serrano, O. 2012. Seagrass ecosystems as a globally significant carbon stock. Nature Geoscience. Florida International University (1-8).

Graha, Y.I., Arthana, I.W. \& Karang, I.W.G.A. 2015. Simpanan Karbon Padang Lamun di Kawasan Pantai Sanur, Kota Denpasar. Program Pascasarjana, Universitas Udayana, Bali. Ecotrophic, 10(1):46-53. DOI: 10.24843/EJES.2016.v10.i01.p08 
Howard, J., Hoyt, S., Isensee, K., Telszewski, M. \& Pidgeon, E. (eds.). 2014. Coastal Blue Carbon: Methods for Assessing Carbon Stocks and Emissions Factors in Mangroves, Tidal Salt Marshes and Seagrasses. Conservation International, Intergovermental Oceanographic Commission of UNESCO, International Union for Conversation of Nature. Arlington, Virginia, USA. $180 p$

Indriani, A.J., Wahyudi \& Yona, D. 2017. Cadangan Karbon di Area Padang Lamun Pesisir Pulau Bintan, Kepulauan Riau. Jurnal Oseanologi dan Limnologi di Indonesia, 2(3):1-11.

Laffoley, D dan Gimsditch G. 2009. The Management of Natural Coastal Carbon Sink. IUCN. Gland Switzerland. 53 pp. ISBN: 978-1205.

McKenzie, Campbell, S.J. \& Roder, C.A. 2003. Seagrasswatch: Manual for Mapping \& Monitoring Seagrass Resources by Community (Citizen) Volunteer. 2rd edition. The State of Queensland. Departement of Primary Industries. CRC Reef. Queensland.114 pp

Nabilla, S., Hartati, R. \& Nuraini, R.A.T. 2019. Hubungan Nutrien Pada Sedimen dan Penutupan Lamun Di Perairan Jepara. Jurnal Kelautan Tropis Maret, 22(1):42-48.

Nellemann, C., Corcoran, E., Duarte, C.M., Valdés, L., DeYoung, C., Fonseca, L. \& Grimsditch, G. 2009. Blue Carbon: The Role of Healthy Oceans in Binding Carbon. A Rapid Response Assessment. United Nations Environment Programme. Norway. ISBN: 978-82-7701-060-1.

Papilo, P., Kunaifi, Erliza, H., Nurmiati \& Rizfi, F.P. 2015. Penilaian Potensi Biomassa Sebagai Alternatif Energi Kelistrikan. Jurnal PASTI, 9(2):164-176.

Rahmawati, S., Irawan, A., Supriyadi, I.H. \& Azkab, M.H. 2014. Panduan Monitoring Padang Lamun (Edt: M. Hutomo dan A. Nontji). CRITC COREMAP CTI Lembaga IImu Pengetahuan Indonesia. 37pp.

Septiani, E.F., Ghofar, A. \& Febrianto, S.. 2018. Pemetaan Karbon Di Padang Lamun Pantai Prawean Bandengan Jepara. Majalah IImiah Globe, 20(2):117-124.

Setiawan, F., Harahap, S.A., Andriani, Y. \& Hutahaean, A.A. 2012. Deteksi Perubahan Padang Lamun Menggunakan Teknologi Penginderaan Jauh dan Kaitannya dengan Kemampuan Menyimpan Karbon di Perairan Teluk Banten. Jurnal Perikanan dan Kelautan, 3(3):275-286.

Smith, P., Field, C.B. \& Raupach, M.R., 2004. Engineered biological sinks on land. The global carbon cycle: integrating humans, climate and the natural world, pp.479-491.

Supriadi, Kaswadji, R.F., Bengen, D.G. \& Hutomo, M. 2014. Carbon Stock of Seagrass Community in Barranglompo Island, Makassar. Jurnal Ilmu Kelautan, 19(1):1-10.

Tasabaramo, I.A., Kawaroe, M. \& Rappe, R.A. 2016. Laju Pertumbuhan, Penutupan Lamun, dan Tingkat Kelangsungan Hidup Enhalus acoroides yang di Transplantasikan Secara Monospesies dan Multispesies. Jurnal IImu dan Teknologi Kelautan Tropis. 7(2):757-770.

Travaille, K., Salinas-de-Leon, P., \& Bell, J. 2015. Indication of Visitor Trampling Impacts on Intertidal Seagrass Beds in a New Zealand Marine Reserve. Ocean \& Coastal Management, 114:145-150.

Wahyudi, A.J., Rahmawati, S., Prayudha, B., Iskandar, M.R. \& Arfianti, T. 2016. Vertical carbon flux of marine snow in Enhalus acoroides- dominated seagrass meadows. Regional Studies in Marine Science, 5:27-34.

Wardah., B. Toknok dan Zulkaidhah. 2009. Persediaan Karbon Tegakan Agroforestri di Zona Penyangga Hutan Konservasi Taman Nasional Lore Lindu, Sulawesi Tengah. Penelitian Strategi Nasional. Universitas Tadulako.

Wawo, M., Wardiatno, Y., Adrianto, L., \& Bengen, D.G. 2014. Carbon stored on seagrass community in marine nature tourism park of Kotania Bay, Western Seram, Indonesia. Jurnal Manajemen Hutan Tropika, 20(1):51-57. 